\title{
SITUAÇÃO DO PÊNFIGO FOLIÁCEO ENDÊMICO EM MATO GROSSO DO SUL, BRASIL, 1990-1999
}

\author{
Aucely Corrêa Fernandes Chagas $^{1}$ \\ Maria Lúcia Ivo ${ }^{2}$ \\ Michael Robin Honer ${ }^{2}$ \\ Ruy Correa Filho ${ }^{2}$
}

Chagas ACF, Ivo ML, Honer MR, Correa R Filho. Situação do pênfigo foliáceo endêmico em Mato Grosso do Sul, Brasil, 1990-1999. Rev Latinoam Enfermagem 2005 março-abril; 13(2):274-6.

Com o objetivo de caracterizar epidemiologicamente o pênfigo foliáceo endêmico, investigaram-se 307 casos. A patologia predominou no trabalhador rural na faixa de 10 a 42 anos. Verificou-se maior incidência em dezembro, janeiro, fevereiro, março e maio (média de 30,7 casos anuais). Os achados evidenciaram um corredor coincidindo com o divisor de águas do estado.

DESCRITORES: epidemiologia; pênfigo; dermatologia

\section{SITUATION OF ENDEMIC PEMPHIGUS FOLIACEUS IN MATO GROSSO DO SUL, BRAZIL, 1990-1999}

307 cases were examined to characterize epidemiological aspects of endemic pemphigus foliaceus. The disease was predominantly identified in rural workers between 10 and 42 years old. Incidence was higher in the December, January, February, March and May (average: 30.7 cases/year). Our findings identified a corridor, coinciding with the state watershed.

DESCRIPTORS: epidemiology; pemphigus; dermatology

\section{SITUACIÓN DEL PÉNFIGO FOLIÁCEO ENDÉMICO EN MATO GROSSO DO SUL, BRASIL, 1990-1999}

Este estudio identificó a 307 casos para caracterizar epidemiológicamente pénfigo foliáceo endémico. La enfermedad predominó en trabajadores rurales, con edad entre 10 y 42 años. Los niveles de incidencia fueron mayores en Diciembre, Enero, Febrero, Marzo y Mayo, con un promedio de 30,7 casos anuales. Los hallazgos mostraron un corredor, coincidiendo con el divisor de agua del Estado.

DESCRIPTORES: epidemiología; penfigo; dermatología

\footnotetext{
${ }^{1}$ Enfermeira, Mestre do Programa de Mestrado em Saúde Coletiva, e-mail: aucely@nin.ufms.br; ${ }^{2}$ Professor Doutor da Universidade Federal de Mato Grosso do Sul, e-mail: ivoms@terra.com.br, e-mail: mrhoner@terra.com.br, e-mail: correaf@zaz.com.br
} 


\section{INTRODUÇÃO}

O pênfigo foliáceo endêmico (PFE) é uma afecção que atinge a cútis superficialmente, com presença de bolhas e dores que dão sensação de queimação. As bolhas facilmente se rompem, deixando áreas erodidas. De início, elas surgem no tórax (anterior e posterior), face e couro cabeludo, podendo espalhar-se pelo corpo, exceto nas mucosas. Não tratadas, evoluem para descamação generalizada ${ }^{(1)}$. Os pacientes desenvolvem sensibilidade a certos antígenos epidérmicos dirigidos contra a desmogleína 1 desmossômica, molécula de adesão celular. A predisposição genética parece ser relevante para a doença ${ }^{(2)}$.

Única doença auto-imune endêmica no mundo ${ }^{(3)}, 0$ PFE era antes conhecido apenas no Brasil, mas, hoje, ocorre também em países africanos e na América do Sul, Colômbia, Bolívia, Paraguai e Peru ${ }^{(4.5)}$, países limítrofes ao Brasil( ${ }^{(6)}$. No Centro-Oeste brasileiro, os casos provêm de focos estabilizados em áreas já colonizadas ${ }^{(7-8)}$. A complexidade do quadro apresentado, etiologia desconhecida e a situação endêmica motivaram a realização deste estudo, que pretende: caracterizar epidemiologicamente os casos novos de pênfigo foliáceo (PF) procedentes do estado de Mato Grosso do Sul e identificar possíveis fatores existentes que predisponham indivíduos à patologia.

\section{MÉTODO}

Este estudo descritivo retrospectivo dos prontuários dos pacientes diagnosticados com PFE atendidos no Hospital Adventista do Pênfigo, considerado de referência na área, cobriu o período de 1990 a 1999, em que foram atendidos 1762 casos. Foram incluídos na amostra somente os dados dos 307 procedentes de Mato Grosso do Sul, considerando-se as variáveis: sexo; faixa etária; ocupação; distribuição mensal da doença; distribuição anual; procedência (por municípios e microrregiões do estado); rede hidrográfica. A coleta foi autorizada pela instituição e pelo Comitê de Ética da UFMS.

\section{RESULTADOS E DISCUSSÃO}

Dos 307 pacientes incluídos, 162 (52,8\%) eram do sexo feminino e 145 (47,2\%) masculino, predominando trabalhadores rurais e a faixa etária de 10-42 anos. Esses resultados têm similitude com os da literatura, onde é enfatizado que a população-alvo é constituída de crianças, adolescentes e adultos jovens ${ }^{(4-5,8-9)}$, com maior incidência entre lavradores e domésticas (procedentes da área rural) ${ }^{(8-10)}$. A distribuição anual dos casos revelou-se estável (média de 30,7 casos/ ano).

Dezembro, janeiro, fevereiro, março e maio foram os meses de maior incidência, o que é corroborado na literatura de duas maneiras: (a) a luz solar é considerada desencadeante do processo; (b) a doença tende a surgir "no verão ou no outono", sendo "novembro, dezembro, janeiro, fevereiro e maio os meses mais associados" a seu início ${ }^{(6)}$. Na estação chuvosa, os rios invadem florestas, arrastando materiais vegetais em decomposição e elevando a quantidade de tanino dissolvido - fenômeno que, nas regiões de clima quente e úmido, é associado à maior incidência da doença ${ }^{(11)}$. A literatura correlaciona fatores ambientais com a doença, destacando o papel dos fenóis (de que os rios são grandes reservatórios) e tióis. As águas de rios são utilizadas para beber, para o banho e para a lavagem de roupas ${ }^{(12)}$. As microrregiões com maior número de casos formam um corredor que coincide com o divisor de águas das bacias dos rios Paraguai e Paraná (Figuras $1 \mathrm{e} 2$ ). Aliteratura realmente aponta que a maioria dos pacientes reside nas proximidades de cursos d'água ${ }^{(2,4,13)}$ e que a maioria dos casos no Brasil ocorre em estados irrigados pelos rios Araguaia, Tocantins, Paraná, Paraguai e seus afluentes ${ }^{(14)}$, devendo-se levar em conta, porém, que os indivíduos com a doença estão expostos a outros fatores ambientais ${ }^{(13,15)}$.
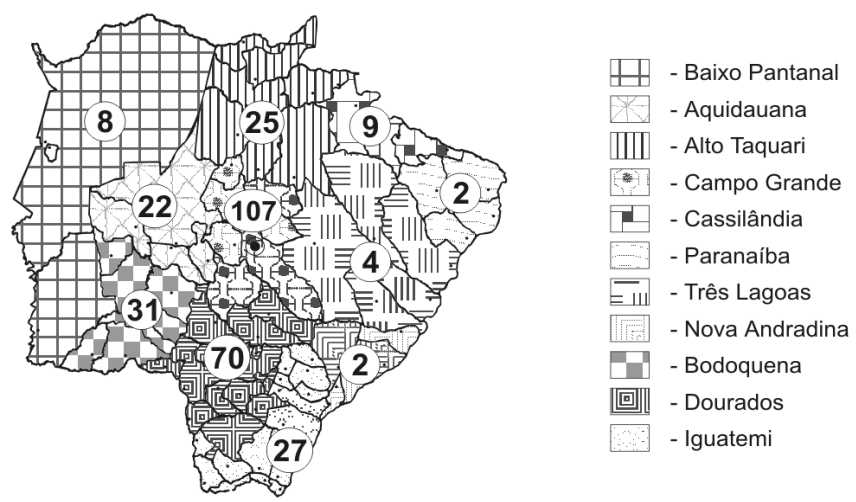

Fonte: IBGE/2000 ${ }^{(16)}$

Figura 1 - Distribuição, segundo as microrregiões de procedência, dos pacientes com pênfigo foliáceo provenientes de Mato Grosso do Sul atendidos no Hospital Adventista do Pênfigo, Campo Grande, MS, 1990-1999

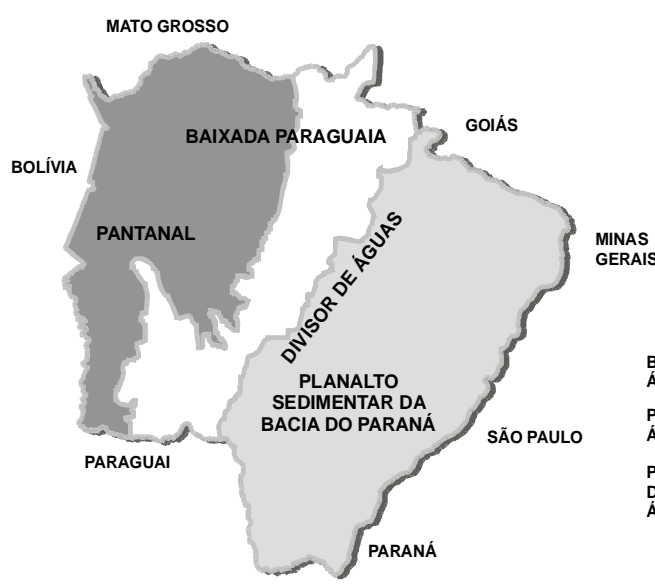

BAIXADA PARAGUAIA PANTANAL AREA: $86.230,00 \mathrm{~km}^{2}$ PLANALTO SEDIMENTAR AREA: $171.558,02 \mathrm{~km}^{2}$

Fonte: Mato Grosso do Sul, $1996^{(17)}$

Figura 2 - Grandes unidades geográficas 


\section{CONCLUSÕES}

O pênfigo foliáceo revelou-se ativo em Mato Grosso do Sul (média de 30,7 casos anuais em 1990-1999, com predomínio de dezembro a março e maio, em indivíduos de 10 a 42 anos que

\section{REFERÊNCIAS BIBLIOGRÁFICAS}

1. Cotran RS, Kumar V, Robbins SL. Robbins patologia estrutural e funcional. $4^{a}$ ed. Rio de Janeiro: Guanabara Koogan; 1991.

2. Sampaio SAP, Rivitti EA. Erupções vésico-bolhosas. In: Sampaio SAP, Rivitti EA. Dermatologia. São Paulo: Artes Médicas; 1998. p.22948.

3. Abréu AM. Pênfigo foliáceo endémico. Acta Med Colomb ene/feb1996; 21(1):27-34.

4. Minelli L. Pênfigo foliáceo sul-americano no estado do Paraná, Brasil, 1941 a 1980. Bol Of Sanit Panam 1986 Aug; 101(2):114-23.

5. Hans G Filho. Endemic pemphigus foliaceus (fogo selvagem)-1998. Clin Dermatol 1999; 17:225-35.

6. Barraviera SR, Dillon NL. Pênfigo foliáceo no Hospital da Faculdade de Medicina de Botucatu, SP. Anais Bras Dermatol nov/dez 1997; 72(6):533-7.

7. Galarza, C, Ronceros Medrano G, Mendonza D, Sánchez G, Vilcaarromero M, Ráez E. Pénfigo foliáceo endémico en el departamento de Ucayali-Perú. Report de 16 casos/Endemic Pemphigus foliaceus at Ucayali departament-Peru. Report of 16 cases. An Fac Med (Perú) 2002; 63(1):19-24.

8. Campbell I. Pênfigo foliáceo endêmico/fogo selvagem/endemic pemphigus foliaceous/fogo selvagem. Anais Bras Dermatol jan/fev 2001; 76(1):13-33.

9. Mansur JS, Mansur MCA, Azulay RD, Breder MNR. Distribuição geográfica do pênfigo foliáceo sul-americano no Estado do Rio de Janeiro. Anais Bras Dermatol 1998 maio; 63(supl):191-8.

10. Chiossi MPV, Roselino AMF. Endemic pemphigus foliaceus ("Fogo selvagem"): a series from the Northeasterm region of the State of São Paulo, Brazil, 1973-1998. Rev Inst Med Tropical 2001 Mar- Apr; 43(2):59-62.

11. Tur E, Brenner S. Diet and pemphigus In pursuit of exogenous factors in pemphigus and fogo selvagem. Arch Dermatol 1998 Nov; 134(1):1406-10.

12. Brenner S. Pemphigus and diet Have we solved the mystery of fogo selvagem. Adv Exp Med Biol 1999; 455:267-9.

13. Crosby DL, Diaz LA. Endemic pemphigus foliaceus: fogo selvagem Dermatol Clin 1993 July; 11(3):453-62.

14. Camisa C, Warner M. Treatment of pemphigus. Dermatol Nurs April 1998; 10(2):123-31.

15. Castro RM, Sampaio SAP. Pênfigo foliáceo brasileiro. In: Talhari S, Neves RG. Dermatologia Tropical. São Paulo: MEDSI; 1997. p.10313.

16. Instituto Brasileiro de Geografia e Estatística-IBGE. Sinopse preliminalar de censo demográfico. Rio de Janeiro (RJ): IBGE; 2000. v.7, p. 1-1:5-5. desempenham ocupações categorizadas como do lar, de trabalho rural e outras, em ambos os sexos). O número de casos de cada microrregião evidencia um corredor norte-sul que coincide com o divisor de águas entre as bacias dos rios Paraguai e Paraná.

17. Secretaria de Estado de Finanças (MS). Orçamento e Planejamento. Diagnóstico Sócio-Econômico de Mato Grosso do Sul, Campo Grande (MS): SEF; 1996. 